\title{
Analysis of WCAG 2.0 data accessibility success criterion of e- government websites
}

\author{
Mohamed Basel Al Mourad ${ }^{1}$, Mohammed Hussein ${ }^{2}$, Faouzi Kamoun ${ }^{3}$, Zelal Wattar ${ }^{4}$ \\ ${ }^{1}$ Zayed University, College of Technological Innvation, UAE, baasel.almourad@zu.ac.ae \\ ${ }^{2}$ Zayed University, College of Technological Innvation, UAE, Mohammed.hussein@zu.ac.ae \\ ${ }^{3}$ Zayed University, College of Communication \& Media Sciences, UAE, zelal.wattar@zu.ac.ae \\ ${ }^{4}$ ESPRIT School of Engineering, Tunisia, Faouzi.kammoun@esprit.tn
}

\section{Article Info}

Received Dec 23, 2018

\section{Keyword:}

Web accessibility

WCAG 2.0

Web accessibility success

criterion

\begin{abstract}
An accessible website enables the access to information and interaction for many people with disabilities so these people can contribute more effectively in the society. Today, most governments are enforcing their websites to follow the www consortium (w3c)'s Web Content Accessibility Guidelines (WCAG 2.0). This paper investigates the WCAG 2.0 success criterions that make a website accessible and explores the most violated WCAG 2.0 success criterions by the developers of e-Government websites.
\end{abstract}

\section{Corresponding Author:}

Mohamed Basel Al Mourad,

College of Technological Innvation,

Zayed University, UAE,

P. O. Box 19282, Dubai, UAE +971 $440121464 \cdot+56223037001$.

Email: basel.almourad@zu.ac.ae

\section{Introduction}

The Web and Internet are an increasingly essential resource in many aspects of human digital life which includes: education, employment, government, commerce, health care, recreation, and more. It is vital that the Web is accessible to everyone in order to provide equal access and equal opportunity to people with disabilities. Web accessibility focuses on people with all types of disabilities - visual, auditory, physical, speech, cognitive, and neurological disabilities - including older people with age-related impairments (Kurt, 2017). Web accessibility means that people with disabilities (i.e. including visual, auditory, physical, speech, cognitive, and neurological disabilities) can perceive, understand, navigate, and interact with the Web, and that they can contribute to the Web (Lawton, 2014).

The main self-regulatory body in relation to access to the Internet is the World Wide Web Consortium (W3C). The $\mathrm{W} 3 \mathrm{C}$ created various working groups to develop web standards, guidelines, and supporting materials within the realm of the Web Accessibility Initiative (WAI) in (W3C, 2018). In 1999, the W3C established the first accessibility standard for the Web, WCAG 1.0. Almost ten years later, in December 2008, the WAI revised the WCAG guidelines and published an updated version (i.e., WCAG 2.0) (WCAG 2.0, 2018). The WCAG 2.0 guidelines are accepted as the primary standard by which accessibility should be measured. They are composed of 12 separate guidelines, organized under 4 principles: perceivability. (meaning that information and user interface components must be presentable to users in ways they can perceive), operability (meaning that user interface components and navigation must be operable), understandability (meaning that information and the operation of the user interface must be understandable), and robustness 
(meaning that content must be robust enough to be interpreted reliably by a wide variety of user agents, including assistive technologies).

Section 2 focuses on the aim of the research. Section 3 presents the research methodology. Section 4 discusses the result of the research.

\section{Aim of the research}

Most governments today are promoting the transition of their countries towards an information-based society where e-Government websites are becoming the primary gateways to citizens and businesses for government information and e-service delivery (Goodwin et al., 2011). E-Government can be broadly defined as the unification of information and communication technologies, and administrative practices to provide government e-services to citizens, businesses and other e-Governments (Basu, 2004). The benefits of online government e-services include better efficiency, user convenience and more citizen political involvement (Freeman and Loo, 2009). To enable all citizens to benefit from the full potential of e-Government services, it is important to secure universal accessibility. This accessibility enables people with disabilities to take full advantage of the information and services offered by e-Governments; the same way a person with no disability would. Despite WCAG 2.0 guidelines have been widely accepted or adopted into policy and legislative frameworks, it is widely reported that the implementation of the WCAG 2.0 guidelines has thus far been quite slow (Kamoun \& Almourad, 2014; Almourad et. al., 2016).

This research has two aims. The first aim is to present an analysis of web accessibility content established by the WCAG 2.0 guidelines. The second aim is to raise awareness among developers and webmasters about the importance of universal accessibility. We have tried to highlight the most violated WCAG 2.0 Success Criterions. This would help developers pay more attention to these success criterions and try to avoid the same mistakes that many developers are falling in.

\section{Research Methodology}

We have adopted a quantitative research method to measure the most violated WCAG 2.0 success criterions and provide guidance for the web developer and webmasters on how to avoid these violations. We selected 19 Dubai e-government websites as a case study for our measurement testing. Several automatic accessibility tools are available to assess web accessibility and which and how many WCAG 2.0 success criterions are violated. There many web accessibility assessment tools that are able to evaluate web site accessibility. We have chosen the AChecker tool (AChecker, 2018) as research demonstrates that this tool achieves better evaluation result than other tools (Pacheco et. El., 2016). The tool can test all the conformance levels (A, AA, and AAA).

AChecker is a holistic accessibility testing tool used to evaluate the HTML content for a single web page. A web page can be tested by entering the URL, uploading an HTML file, or by pasting the source code directly into the tool. AChecker provides a personalized accessibility assessment methodology, allowing users to select between different set of accessibility guidelines, impairments, and personas. The tool can test conformance against all the conformance levels (A, AA, and AAA). AChecker identifies 3 types of problems:

- Known problems: These are problems that have been identified with certainty as accessibility barriers. The web page must be modified to fix these problems;

- Likely problems: These are problems that have been identified as probable barriers but require a human to make a decision. The web page likely needs to be modified to fix these problems.

- Potential problems: These are problems that AChecker cannot identify, that require a human decision.

We used AChecker to test accessibility conformance on the 19 Dubai e-Government Websites. For each website we extracted the number of issues for each violated checkpoint. We gathered all the extracted numbers in an Excel sheet for analysis.

\section{4. $\quad$ Result \& Discussion}

Table 1 summarizes the number of violations of every success criterion for each tested Dubai e-government website. The website names are hidden for confidentiality and have been renamed Q1 to 19. For the purpose 
of condensing this paper, we have only included the success criterions that are violated. The success criterions that are not violated are omitted from this discussion.

Table 1 checkpoint violations by every organization

\begin{tabular}{|c|c|c|c|c|c|c|c|c|c|c|c|c|}
\hline & \multicolumn{4}{|c|}{ Perceivable } & \multicolumn{4}{|c|}{ Operable } & \multicolumn{2}{|c|}{ Understandable } & \multirow{2}{*}{$\begin{array}{c}\text { Robust } \\
4.1\end{array}$} & \multirow[b]{3}{*}{ 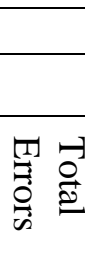 } \\
\hline & 1.1 & 1.3 & & .4 & 2.1 & 2.2 & & .4 & 3.1 & 3.3 & & \\
\hline Organization & $\stackrel{\vec{E}}{\vec{E}}$ & $\vec{i}$ & 变京 & 蛋市 & 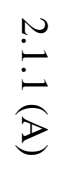 & $\stackrel{N}{\stackrel{N}{N}}$ & $\begin{array}{l}\stackrel{N}{+} \\
\stackrel{+}{+} \\
\mathbb{E}\end{array}$ & B & $\begin{array}{l}\dot{\omega} \\
\stackrel{\oplus}{\oplus}\end{array}$ & $\underset{\stackrel{w}{w}}{\stackrel{w}{i}}$ & $\stackrel{+}{\stackrel{D}{E}}$ & \\
\hline Q1 & 16 & & 58 & 3 & & & & 1 & 1 & & & 89 \\
\hline $\mathrm{Q} 2$ & 1 & 11 & 1 & & & & 3 & 8 & 1 & 12 & & 37 \\
\hline Q3 & & & 95 & & & & & & 1 & & & 96 \\
\hline Q4 & & & 5 & 1 & & & 2 & & & & 1 & 9 \\
\hline Q5 & 18 & & & 3 & & & & & 1 & & 1 & 23 \\
\hline Q6 & 1 & & 16 & 5 & & & & & & & & 22 \\
\hline Q7 & 75 & 41 & 3 & 5 & 2 & & 4 & & 1 & 25 & & 156 \\
\hline Q8 & & 14 & 9 & 5 & 1 & & & & 1 & 10 & 2 & 57 \\
\hline Q & 2 & & 20 & & 2 & & & & 1 & & 1 & 26 \\
\hline Q10 & 13 & & & & & & & 1 & & & 1 & 15 \\
\hline Q11 & 1 & 2 & 5 & & & & 14 & 2 & & 1 & & 25 \\
\hline Q12 & 3 & 2 & 6 & & & & & & & & 1 & 12 \\
\hline Q13 & 6 & 4 & 53 & 5 & & & 7 & 5 & & & & 80 \\
\hline Q14 & 9 & 6 & 17 & 6 & & & & & & & & 38 \\
\hline Q15 & & & & & & & & 1 & & 8 & 1 & 10 \\
\hline Q16 & 10 & 4 & & 1 & & & & & 1 & & 1 & 17 \\
\hline Q17 & 3 & & 103 & 28 & & & & 2 & & & & 136 \\
\hline Q18 & 9 & & 81 & 1 & & 1 & & 1 & 1 & & 1 & 95 \\
\hline Q19 & & 6 & 2 & & & & & 2 & & 3 & & 13 \\
\hline $\begin{array}{l}\text { Total Errors } \\
\text { per } \\
\text { Organization }\end{array}$ & 182 & 90 & 474 & 73 & 5 & 1 & 30 & 23 & 9 & 59 & 10 & \\
\hline
\end{tabular}

As shown in table 1, none of the 19 tested websites have passed the test. All organizations have accessibility errors. However, websites (Q4, Q12, O15 and Q19). have generated less than 15 accessibility errors (see Figure 1)

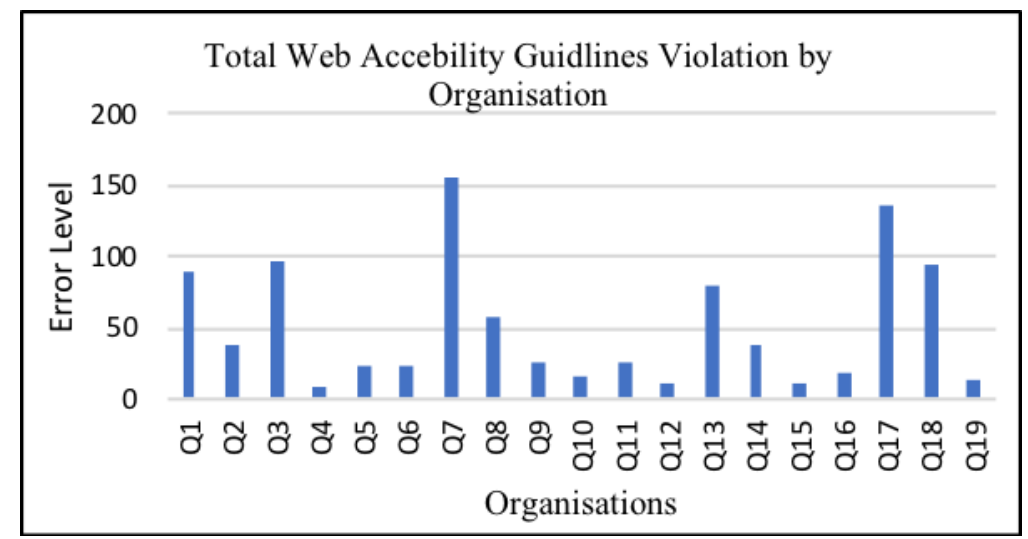

Figure 1 Total Web Accessibility Guidelines Violation by Organization 
As shown in Figure 2, success criterion 1.1.1, 1.4.4, 1.3.1, 1.4.6, 3.3.2 and 2.4.4 are the most violated success criterion. In the following discussion, we will be analysing the success criterion and ignoring the success criterions that are violated fewer times and less frequently.

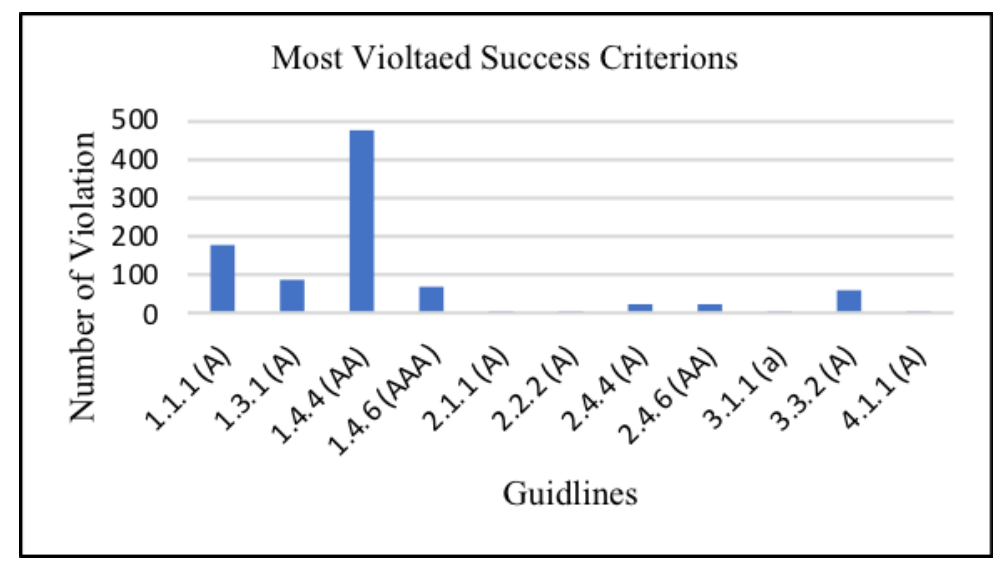

Figure 2 The Most Violated Success Criterion

Success criterion 1.1.1 belongs to conformance level A. It was violated 182 times (Figure 3). The aim of this success criterion is to make information conveyed by non-text content accessible through the use of a text alternative: "All non-text content that is presented to the user has a text alternative that serves the equivalent purpose". For example, some users browse websites with images turned off. These must be true alternative text that describes the image content.

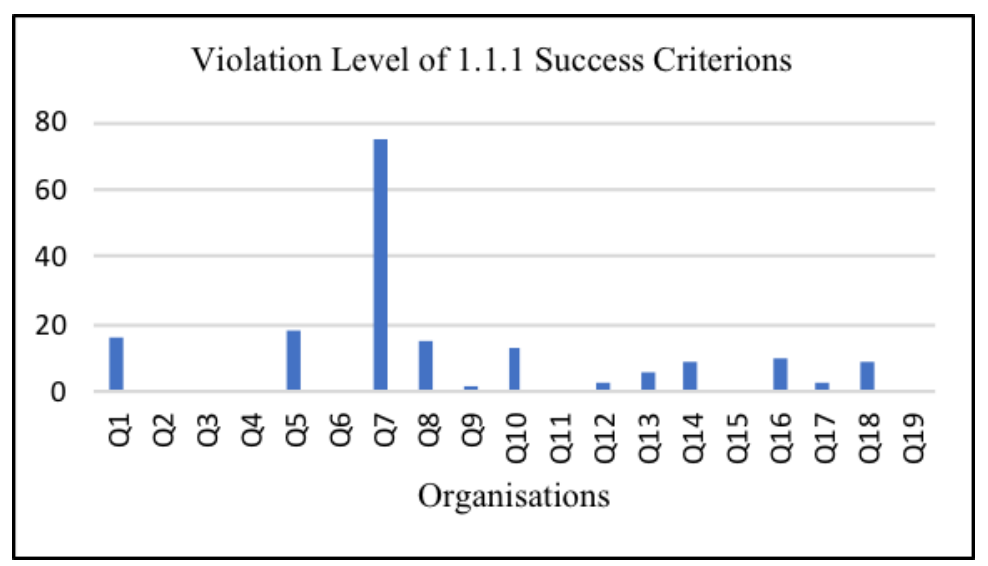

Figure 1 Violation Level of 1.1.1 Success Criterion

Success criterion 1.4.4 belongs to conformance level AA and it was violated 474 times (Figure 4). The aim of this success criterion is that text is scaled so that it can be read directly by people with mild visual disabilities, without requiring the use of assistive technology such as a screen magnifier. Website users may attempt to scale all content on the Web page, but text is most critical. Normally the user agent will provide support for zooming in and out of a page. Note that zooming in a browser (usually keys 'Ctrl+' or 'Ctrl-') may work differently from just increasing the text size. If the text size is increased, it may not necessarily increase the size of images whereas zooming generally increases the size of all content in the page. To meet this success criterion, the website should allow for up to a $200 \%$ resize of text without dropping any content or functions. 


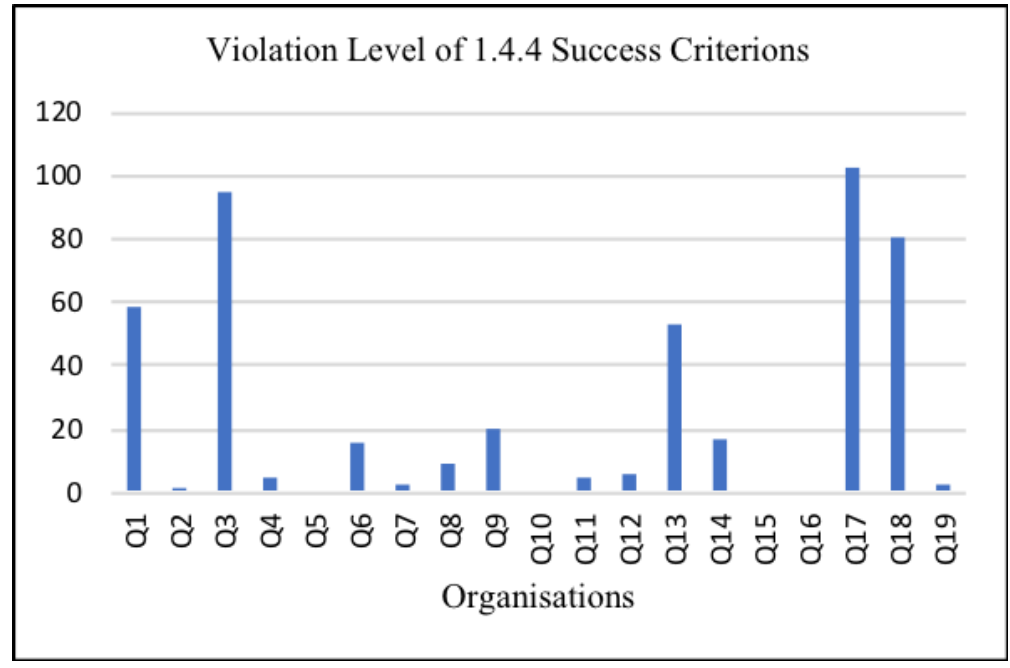

Figure 2 Violation Level of 1.4.4 Success Criterion

Success criterion 1.3.1 belongs to conformance level AA. It was violated 90 times (Figure 5). The aim of this success criterion is to ensure that any information and relationships specified by visual (or audio) methods may be determined programmatically by assistive technologies or a text description of the information and relationship provided where this may not be possible. Users who are blind (using a screen reader) benefit when information conveyed through colour is also available in text. For example, a form contains several required fields. The labels for the required fields are displayed in red.

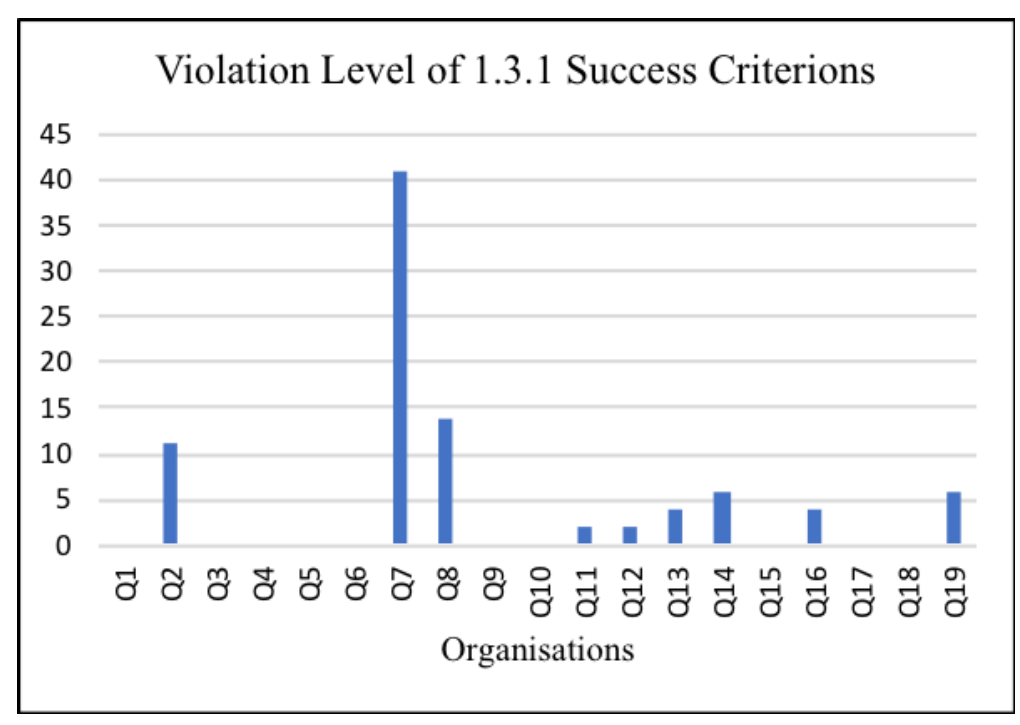

Figure 3 Violation Level of 1.3.1 Success Criterion

Success criterion 1.4.6 belongs to conformance level AAA. It was violated 73 times (Figure 6). The aim of this success criterion is to provide enough contrast between text and its background so that it can be read by people with moderately low vision. The visual presentation of text and images of text has a contrast ratio of at least 7:1. A colour contrast analyser would be needed to ascertain the ratio of the selected colours. 


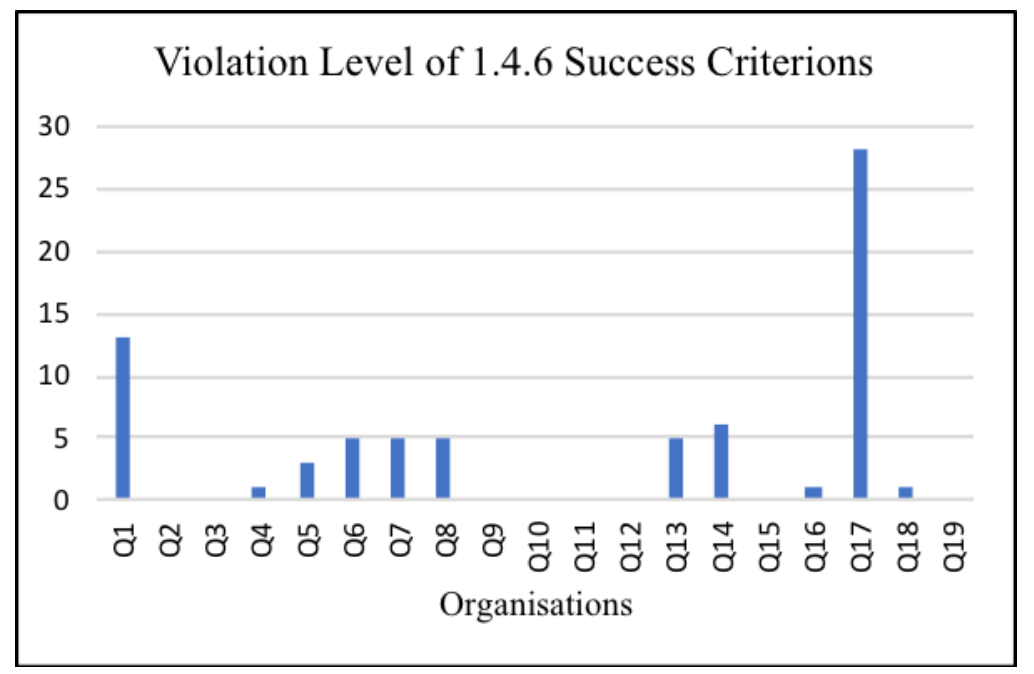

Figure 4 Violation Level of 1.4.6 Success Criterion

Success criterion 3.3.2 belongs to conformance level A. It was violated 59 times (Figure 7). The aim of this success criterion is to have content where authors place instructions or labels that identify the controls in a form so that users know what input data is expected. For example, when labels are used, they should be described appropriately. In a form, the label should correctly identify the field and also identify required fields.

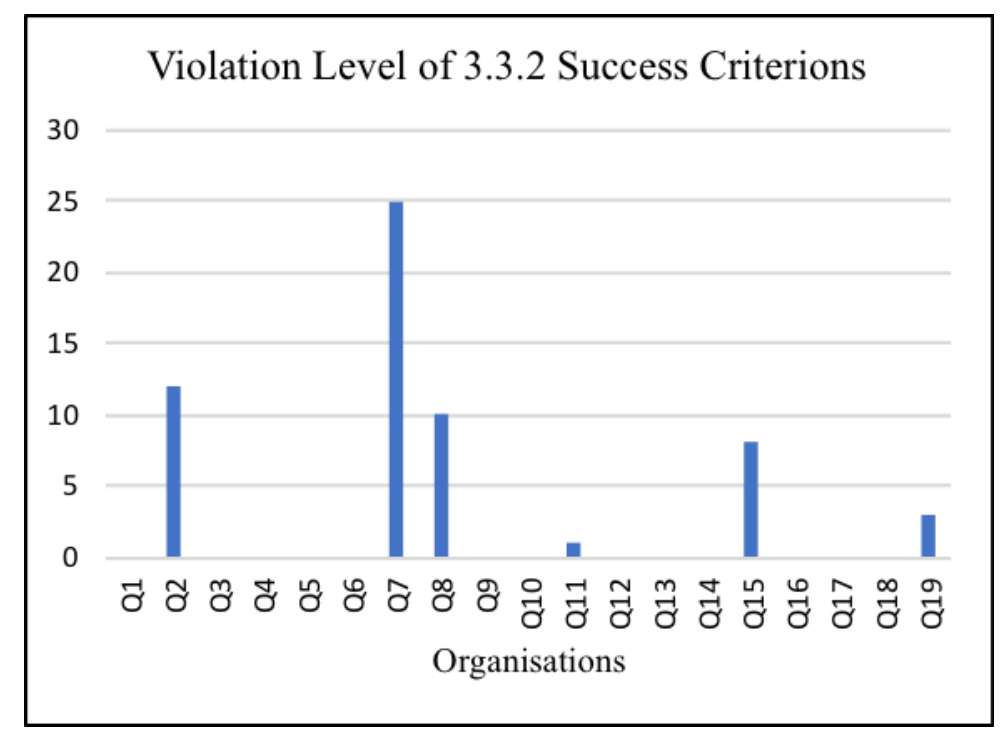

Figure 7 Violation Level of 3.3.2 Success Criterion

Success criterion 2.4.4 belongs to conformance level A. It was violated 30 times. The aim of this Success Criterion is to help users understand the purpose of each link so they can decide whether they want to follow the link. This includes providing link text that identifies the purpose of the link without needing additional context wherever possible. Assistive technology has the ability to provide users with a list of links that are on the Web page. Link text that is as meaningful as possible will aid users who want to choose from this list of links. Meaningful link text also helps those who wish to tab from link to link. Meaningful links help users choose which links to follow without requiring complex strategies to understand the page. For example, the text for the link should describe exactly the purpose of the link rather than a vague name of the page it's will take you to or its URL. 


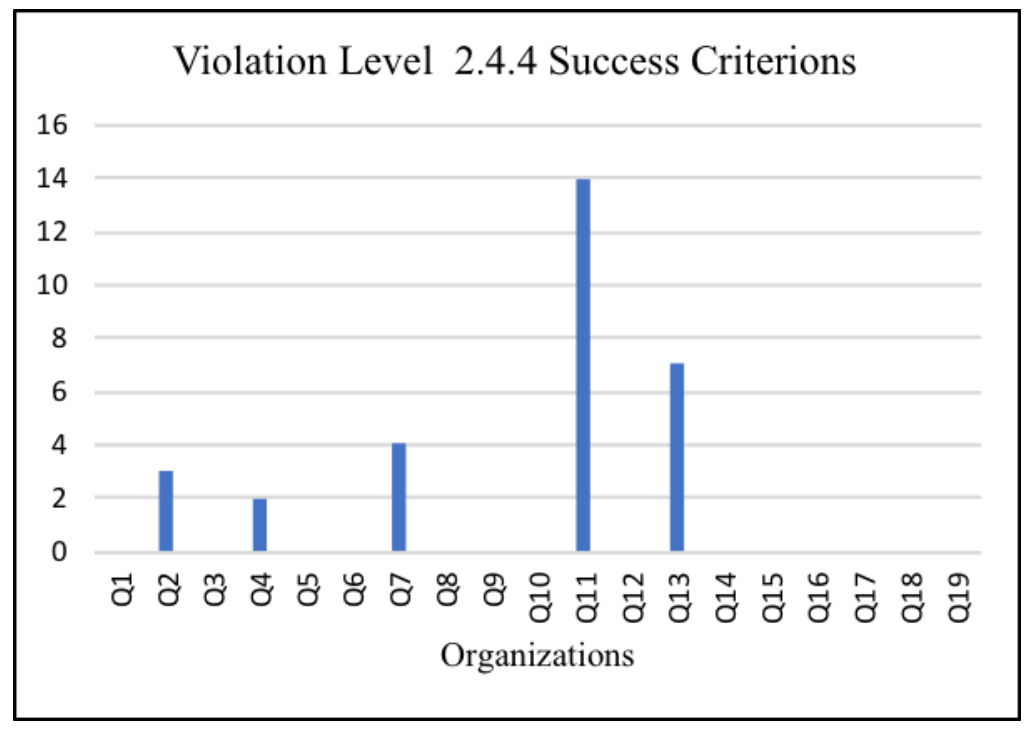

Figure 5 Violation Level 2.4.4 Success Criterion

\section{Conclusion}

None of the 19 tested e-Government websites were fully WCAG 2.0 accessible. Some e-Government websites have generated fewer accessibility errors. Many of the WCAG 2.0 success criterions are violated. We have discussed the most violated accessibility success criterions. Our aim is to raise the awareness to the web developers so these criterions can be avoided in the future and eventually making e-Government web sites more accessible by all members of the society.

\section{References}

[1] S. Kurt. "Accessibility of Turkish University web sites". Universal Access in the Information Society, Volume 16, 2, PP 505 - 515. 2017

[2] S. L. Henry, S. Abou-Zahra, J. Brewer. "The Role of Accessibility in a Universal Web". Proceedings of the 11th Web for All Conference on - W4A '14, Seoul, Republic of Korea, April 7-9, 2014.

[3] F. Kamoun, M. B. Almourad. Accessibility as an integral factor in e-government web site evaluation: The case of Dubai e-government, Journal of Information Technology \& People, Volum 27, I 2, PP 208-228, 2014, Emerald Group Publishing Limited

[4] M. B. Almourad. "The Most Violated WCAG 1.0 Guidelines by the Developers of e-Government Websites", Lecture Notes on Software Engineering, Volume 4, I 3, 2016, IACSIT Press

[5] M. Goodwin, D. Susar, A. Nietzio, M. Snaprud, C. S. Jensen. "Global Web Accessibility Analysis of National Government Portals and Ministry Web Sites", Journal of information Technology and Politics, 8(1), pp. 41--67 (2011).

[6] S. Basu. "E-Government and Developing Countries: An Overview international review of law computers \& technology", volume 18, no. 1, pages 109-132, 2004

[7] R. Freeman, P. Loo. "Web 2.0 and e-government at the Municipal Level", In Proc. $5^{\text {th }}$ International Conference on e-government, 2009, Boston, MA.

[8] AChecker (2018) http://achecker.ca/documentation/index.php?p=checker/index.php , consulted 21 Nov 2018.

[9] S. P. Humberto, F. A. Patricia, G. F. Barbosa Priscyla, B. L. Ferreira Simone. "Comparative Analysis of Web Accessibility Evaluation Tools". In Proceedings of the 15th Brazilian Symposium on Human Factors in 
Computing Systems (IHC '16). ACM, New York, NY, USA, Article 45, 2016.

Web sites:

W3C. Briefing Package for Project Web Accessibility Initiative (WAI). Available online: http://www.w3.org/WAI/References/access-brief (accessed on 30 April 2018)

Web Content Accessibility Guidelines (WCAG 2.0). W3C Recommendation 11 December 2008. Available online: https://www.w3.org/TR/WCAG20/ (accessed on 30 April 2018) 